\title{
A single-gene biomarker identifies breast cancers associated with immature cell type and short duration of prior breastfeeding
}

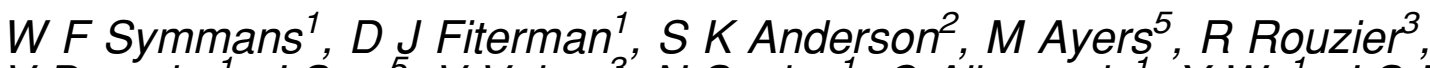

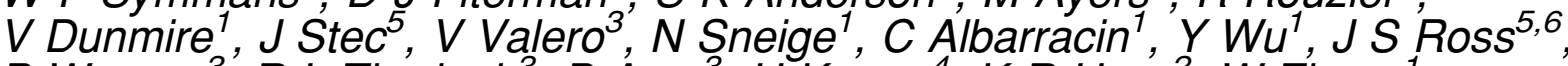

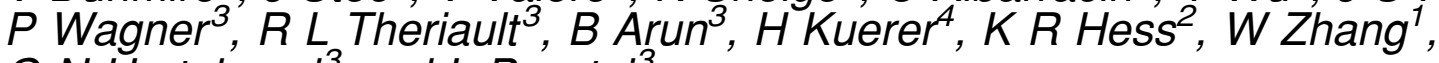 \\ G N Hortobagyi $i^{3}$ and L Pusztai ${ }^{3}$
}

\author{
Departments of ${ }^{1}$ Pathology, ${ }^{2}$ Biostatistics and Applied Mathematics, ${ }^{3}$ Breast Medical Oncology and ${ }^{4}$ Surgery, University of Texas \\ M D Anderson Cancer Center, 1515 Holcombe Boulevard, Houston, TX 77030-4009, USA \\ ${ }^{5}$ Millennium Pharmaceuticals, Inc., 75 Sidney Street, Cambridge, MA 02139, USA \\ ${ }^{6}$ Department of Pathology, Albany Medical College, 47 New Scotland Avenue, Albany, NY 12208-3479, USA
}

(Requests for offprints should be addressed to W F Symmans; Email: fsymmans@mdanderson.org)

\begin{abstract}
The pathogenesis of breast cancers that do not express estrogen receptors or Her-2/neu receptors (ER-/HER2 - phenotype) is incompletely understood. We had observed markedly elevated gene expression of gamma-aminobutyric acid type $A\left(G A B A_{A}\right)$ receptor subunit $\pi(G A B A \pi, G A B R P)$ in some breast cancers with ER-/HER2 - phenotype. In this study, transcriptional profiles (TxPs) were obtained from 82 primary invasive breast cancers by oligonucleotide microarrays. Real-time reverse transcription-polymerase chain reaction (RT-PCR) was used to measure GABA $\pi$ gene expression in a separate cohort of 121 invasive breast cancers. GABA $\pi$ gene expression values from TxP and RT-PCR were standardized and compared with clinicopathologic characteristics in the 203 patients. GABA $\pi$ gene expression was increased in $16 \%$ of breast cancers (13/82 TxP, 20/ 121 RT-PCR), particularly in breast cancers with ER-/HER2 - phenotype (60\%), and breast cancers with basal-like genomic profile (60\%). The profile of genes coexpressed with GABA $\pi$ in these tumors was consistent with an immature cell type. In multivariate linear regression analysis, the level of GABA $\pi$ gene expression was associated with ER-/HER2 - phenotype $(P<0.0001)$, younger age at diagnosis $(P=0.0003)$, and shorter lifetime duration of breastfeeding ( $\leq 6$ months) in all women $(P=0.017)$ and specifically in parous women $(P=0.013)$. GABA $\pi$ gene expression was also associated with combinations of high grade with ER-/HER2 - phenotype $(P=0.002)$, and with Hispanic ethnicity $(P=0.036)$. GABA $\pi$ gene expression is increased in breast cancers of immature (undifferentiated) cell type and is significantly associated with shorter lifetime history of breastfeeding and with high-grade breast cancer in Hispanic women.
\end{abstract}

Endocrine-Related Cancer (2005) 12 1059-1069

\section{Introduction}

Estrogen receptor (ER) and Her-2/neu receptor (HER2) are major determinants of growth and overall gene expression in breast cancer (Perou et al. 2000a, Pusztai et al. 2003). However, invasive breast cancers with negative ER and HER2 status (ER-/HER2-) are not well characterized with respect to the molecular determinants of cancer cell growth and selection of targeted molecular therapies.
We observed markedly elevated gene expression of gamma-aminobutyric acid type $\mathrm{A}\left(\mathrm{GABA}_{\mathrm{A}}\right)$ receptor subunit $\pi$ (GABA $\pi$, GABRP, Unigene NM_014211) in ER-/HER2 - breast cancers from a preliminary screen of cDNA microarrays from 45 breast cancers. $\mathrm{GABA}_{\mathrm{A}}$ receptor subunits assemble in pentameric, ligand-gated chloride ion channel complexes in the cell membrane, although it has not yet been determined whether GABA $\pi$ naturally incorporates into these receptor complexes (Hedblom \& Kirkness 1997, 
Neelands \& MacDonald 1999). Jiang et al. (2002) identified GABA $\pi$ gene expression in breast cancers from subtracted cDNA libraries. Those authors detected GABA $\pi$ transcripts in $10 / 27$ primary breast cancers $(37 \%)$ by semiquantitative reverse transcriptionpolymerase chain reaction (RT-PCR), but the tumor samples were not further characterized (Zehentner et al. 2002).

GABA $\pi$ is not expressed in normal adult neuronal tissues (unlike other $\mathrm{GABA}_{\mathrm{A}}$ subunits), but it is expressed in endocrine and reproductive tissues (Hedblom \& Kirkness 1997). Induction of GABA $\pi$ gene expression has been described in the uterus at the time of implantation and also immediately before parturition (Majewska et al. 1989, Laurie et al. 1992, Fujii \& Mellon 2001), possibly related to the levels of an active progesterone metabolite, allopregnanolone (Hedblom \& Kirkness 1997, Fujii \& Mellon 2001). Breast tissues undergo major physiologic changes during pregnancy and postpartum, so it is reasonable to propose that GABA $\pi$ expression in breast tissues might be related to the endocrinology of reproduction or lactation. It follows, therefore, that elevated GABA $\pi$ expression in a subset of breast cancers could be associated with specific patient characteristics, including reproductive and/or lactation history.

\section{Materials and methods}

\section{Biopsy samples}

A cohort of 203 newly diagnosed invasive breast cancers were evaluated, 82 by Affymetrix GeneChip oligonucleotide gene expression microarrays (TxP), and 121 by real-time RT-PCR (TaqMan). Fine-needle aspiration (FNA) samples were collected from 82 patients with newly diagnosed pretreatment invasive breast carcinomas and were prepared for genomic analysis (Pusztai et al. 2003, Symmans et al. 2003). This study was conducted at the University of Texas M D Anderson Cancer Center (MDACC) and was approved by the institutional review board of MDACC (IRB protocol LAB-99-402). All patients signed an informed consent for voluntary participation. FNA samples were obtained with 23 gauge needles (1-2 passes), mixed in $1.0 \mathrm{ml}$ RNAlater RNA stabilization reagent (Ambion, Inc., Austin, TX, USA), held at room temperature for $30 \mathrm{~min}$ and stored at $-80^{\circ} \mathrm{C}$. Cytologic samples were also collected from 121 surgical resection specimens containing newly diagnosed, invasive breast carcinoma (IRB protocol LAB-03-432), using 23 gauge needles (six passes) or cytologic scrapes with a no. 15 surgical blade, mixed into $1.0 \mathrm{ml} \mathrm{RNA}$ later and stored at $-80^{\circ} \mathrm{C}$.

All 203 samples were also annotated with the corresponding results of standard pathologic assays for ER with immunohistochemistry (monoclonal antibody clone 6F11, Novocastra Labs, Newcastle, UK) and HER2 with immunohistochemistry (monoclonal antibody clone Ab8, Lab Vision, Freemont, CA, USA) and/or fluorescent in situ hybridization (FISH) with probes to detect c-erbB-2 and the centromere of chromosome 17 (Vysis, Downers Grove, IL, USA) (Harvey et al. 1999, Elledge et al. 2000, Ogura et al. 2003, Sapino et al. 2003). ER-positive status was defined as immunohistochemical (IHC) staining in $\geq 10 \%$ of cancer cell nuclei. HER2-positive status was defined as an IHC score of $3+$ membranous staining and/or a FISH score of relative gene copy number of $>2.0$ (ratio of c-erb-B2/centromere 17). All tumors with $1+$ or $2+$ membranous staining for HER 2 were tested for gene copy number by FISH.

\section{RNA extraction}

Total RNA was extracted from 82 thawed in vivo FNA samples with the RNeasy Kit (Qiagen). At least $1 \mu \mathrm{g}$ total RNA with a $260 / 280$ ratio of $>1.8$ by spectrophotometry (DU640 UV; Beckman Coulter, Fullerton, CA, USA) was required for transcriptional profiling. Total RNA was extracted from 121 ex vivo cytologic samples, using a modified protocol of the RNAqueous RNA isolation system (Ambion). Briefly, FNA samples $(1.0 \mathrm{ml})$ were homogenized in $3.0 \mathrm{ml}$ lysis-binding solution (cell pellets were homogenized in $1.0 \mathrm{ml}$ ). An equal volume of ethanol $(64 \%)$ was then mixed into each sample, the mixture was passed through the filter cartridges provided, and the rest of the extraction protocol was followed (Ambion). RNA yield and quality were assessed with an Agilent 2100 Bioanalyzer (Agilent, Palo Alto, CA, USA). A ratio of $28 \mathrm{~s} / 18 \mathrm{~s}$ RNA in the range 1.5-2.5 indicated high-quality RNA free of degradation. RNA samples were stored at $-80^{\circ} \mathrm{C}$.

\section{Transcriptional profiles (TxP)}

Transcriptional profiling was performed at Millennium Pharmaceuticals (Cambridge, MA, USA) on 82 in vivo FNA biopsies of breast cancer. The GeneChip system (Affymetrix, Santa Clara, CA, USA) was used for hybridization, labeling, and scanning of the U133A and B arrays. Microarray Suite 5.0 was used for data acquisition and preliminary analysis. Generation of cRNA followed a standard T7 amplification protocol. Total RNA was reverse-transcribed with SuperScript 
II (Gibco, Carlsbad, CA, USA) in the presence of T7-(dT) $)_{24}$ primer to generate first-strand cDNA. A second-strand cDNA synthesis was performed in the presence of DNA polymerase I, DNA ligase, and RNase $\mathrm{H}$ (Gibco). The resulting double-stranded cDNA was blunt-ended with T4 DNA polymerase. This double-stranded cDNA was then transcribed into cRNA in the presence of biotin-ribonucleotides, using the BioArray High Yield RNA transcript labeling kit (Enzo Life Sciences, Farmingdale, NY, USA). The amplified, biotin-labeled cRNA was purified with RNeasy columns (Qiagen), quantified and fragmented at $94{ }^{\circ} \mathrm{C}$ for $35 \mathrm{~min}$ in the presence of fragmentation buffer $(\times 1)$. Fragmented cRNA was hybridized to Affymetrix U133A chips overnight at $42^{\circ} \mathrm{C}$. To control for hybridization efficiency, a standard probe cocktail supplied by Affymetrix was spiked into the hybridization mix. The software checked for the expression of all known housekeeping genes represented on the chip. For housekeeping genes on the chip, a ratio of the signal obtained for $3^{\prime}$ and $5^{\prime}$ probes is used as an indicator of the efficiency of cRNA preparation. Ratios of 1.0-3.0 indicate acceptable cRNA preparation. Affymetrix data were quantified and normalized with dCHIP V1.3 (http://biosun1. harvard.edu/complab/dchip/data) (Li \& Hung Wong 2001).

\section{Real-time quantitative RT-PCR}

Real-time quantitative RT-PCR was performed with TaqMan 7700 technology (Applied Biosystems, Foster City, CA, USA). One-step RT and PCR was performed. A volume of $10 \mu \mathrm{l}$ RNA (5 ng total) was mixed with $11.25 \mu 1$ nuclease-free water (Invitrogen), $25 \mu \mathrm{l} \times 2$ Master Mix without UNG (Applied Biosystems), $1.25 \mu 1 \times 40$ Multiscribe and RNase Inhibitor (Applied Biosystems), and $2.5 \mu 1 \times 20$ Assay-onDemand (Applied Biosystems) predeveloped primerprobe sets for GABA $\pi$ gene $\left(\mathrm{Hs} 00204411 \_\mathrm{m} 1\right)$ or an endogenous control gene (cyclophilin A, 4326316E) in each well of a 96-well optical plate. Expression of $\mathrm{GABA} \pi$ and the endogenous control gene was evaluated, relative to Stratagene's Universal Human Reference, in triplicate for each sample by the $\mathrm{Ct}$ method. The plates were incubated for $30 \mathrm{~min}$ at $48^{\circ} \mathrm{C}$ and $10 \mathrm{~min}$ at $95^{\circ} \mathrm{C}$, and then 40 cycles of $95^{\circ} \mathrm{C}$ for $15 \mathrm{~s}$ and $60^{\circ} \mathrm{C}$ for $1 \mathrm{~min}$.

\section{Clinical and pathologic correlation}

Clinical information was obtained from the patient record and then delinked from patient identifying information prior to statistical analysis. Age at diagnosis (in years), race (white, black, Hispanic and all others), family history of breast or ovarian cancer in a first-degree relative (none, any), reproductive history (gravida $(0,1,2,3$ or $\geq 4)$, parity $(0,1,2,3$ or $\geq 4)$, abortion $(0,1$ or $\geq 2)$ and age at first pregnancy $(\leq 19$, $20-24,25-29$ or $\geq 30$ years)), and lactation history as lifetime duration of breastfeeding (none, $\leq 6$ months, 6-12 months or $\geq 12$ months) were recorded. Pathologic information included grade (low (1), intermediate (2) or high (3)) according to the modified Black's nuclear grading system, primary tumor stage (T1-T4), regional nodal stage (N0-N3), ER status (positive if $\geq 10 \%$ ), and HER2 status (positive if FISH ratio of $>2.0$ or IHC $3+$ and FISH unknown).

\section{Statistical methods}

Expression values of GABA $\pi$ from the TxP and RT-PCR experiments underwent logarithmic transformation and standardization to a mean of zero and standard deviation of 1.0. Standardized GABA $\pi$ expression values were ranked to demonstrate the threshold value that best separated higher from lower expression of GABA $\pi$ in the TxP data and the RT-PCR data. These standardized expression values were used as a continuous variable for statistical comparisons with the clinical and pathologic variables in univariate analyses and in multivariate analyses using S-PLUS 6.1 for Windows software (Seattle, WA, USA). Linear regression models and ANOVA tests were used to determine the significance of the data, unless otherwise noted. Statistical significance was defined as $P<0.05$.

\section{Results}

GABA $\pi$ gene expression values were higher in ER-/ HER 2- breast cancers in the cohort of 82 breast cancer TxPs, using Affymetrix U133A microarrays (Fig. 1A), and also in an independent cohort of 121 breast cancers, using quantitative RT-PCR (Fig. 1B). The standardized gene expression values for GABA $\pi$ from the TxP and RT-PCR data both demonstrated the greatest increase in GABA $\pi$ expression at the 16.3 percentile, so a standardized GABA $\pi$ gene expression value of $>1.1$ (in $16 \%$ of invasive breast cancers) was defined as high GABA $\pi$ expression. The breast cancers with high GABA $\pi$ expression (standardized value of $>1.1)$ usually had ER-/HER2 - phenotype $(31 / 33$, $94 \%$ ) (Table 1$)$, and were high grade $(27 / 33,81 \%)$ or intermediate grade $(6 / 33,19 \%)$. Overall, $26 \%(52 / 203)$ of invasive breast cancers had ER-/HER2- phenotype, but $60 \%$ of those tumors $(31 / 52)$ also had high 
A

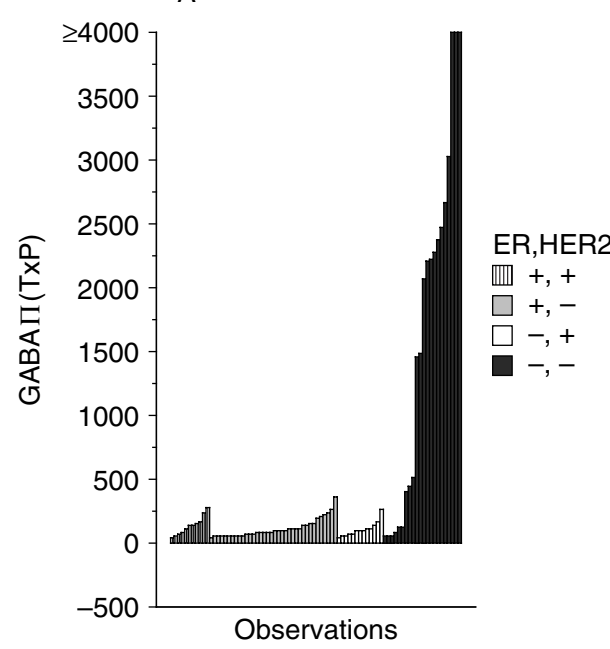

B

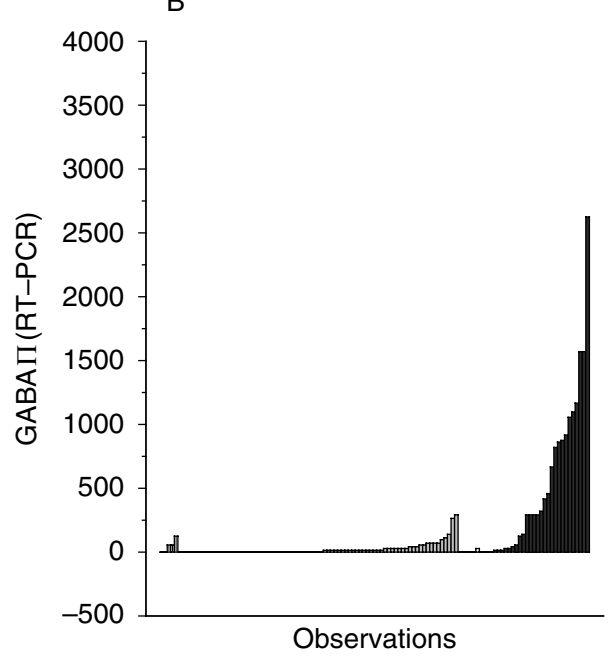

Figure 1 Univariate bar graphs to demonstrate the gene-expression levels for GABA $\pi$ (arbitrary units, $y$-axis) according to combined ER and HER2 phenotype. (A) GABA $\pi$ gene expression from the transcriptional profiles (TxPs) of 82 breast cancer samples; (B) GABA $\pi$ gene expression from quantitative RT-PCR (TaqMan) of an additional 121 breast cancer samples.
GABA $\pi$ gene expression (Table 1). This was significantly more frequent than in other breast cancer phenotypes $($ ER + /HER $2-(2 / 116,2 \%), \quad$ ER - /HER2+ $(0 / 20,0 \%)$, or ER+/HER2+ $(0 / 15,0 \%), P<0.0001)$ (Table 1). Table 1 also shows the Wilcoxon rank sum $P$ values for testing GABA $\pi$ gene expression in ER-/ HER2 - phenotype versus all others. The GABA $\pi$ gene expression level was significantly higher for the ER-/HER2- phenotype overall and separately for TxP and RT-PCR patients.

We were also able to demonstrate the association of GABA $\pi$ gene expression with ER-/HER2- tumors by comparing the relative gene expression levels of GABA $\pi$ (GABRP, probe set 205044), ER (ER- $\alpha$ gene, ESR1, probe set 205225) and HER2 (c-erbB-2 gene, ERBB2, probe set 216836) in the 82 TxPs from Affymetrix U133A microarrays. The relative expression of $\mathrm{GABA} \pi$, ESR1 and $\mathrm{ERBB} 2$ genes in these 82 tumors appeared to be divergent, although some tumors have low expression of all three genes (Fig. 2).

For further investigation of whether high GABA $\pi$ expression represents a particular lineage of differentiation, we classified the 82 transcriptional profiles into

Table 1 Frequency of high GABA $\pi$ gene expression (defined as standardized value $>1.1$ ) in different ER and HER2 phenotypes for 82 breast cancers evaluated with transcriptional profiling (TxP), and 121 other breast cancers studied with RT-PCR. Elevated GABA $\pi$ gene expression is significantly associated with ER-/HER2-phenotype (Wilcoxon rank sum test, $P<0.001$ )

\begin{tabular}{|c|c|c|c|c|c|}
\hline & $\%$ Total & GABA $\pi$ high $(>1.1)$ & Overall & $\%$ GABA $\pi$ high & $P$ value \\
\hline \multicolumn{6}{|l|}{ TxP } \\
\hline ER-/Her2- & 26 & 13 & 21 & 62 & \\
\hline ER-/Her2+ & 17 & 0 & 14 & 0 & \\
\hline $\mathrm{ER}+/ \mathrm{Her} 2-$ & 45 & 0 & 37 & 0 & \\
\hline \multirow{2}{*}{$\mathrm{ER}+/ \mathrm{Her} 2+$} & 12 & 0 & 10 & 0 & \\
\hline & Totals & 13 & 82 & 16 & $P<0.001$ \\
\hline \multicolumn{6}{|l|}{ RT-PCR } \\
\hline ER-/Her2- & 26 & 18 & 31 & 58 & \\
\hline ER-/Her2+ & 5 & 0 & 6 & 0 & \\
\hline $\mathrm{ER}+/$ Her2- & 65 & 2 & 79 & 3 & \\
\hline \multirow{2}{*}{$\mathrm{ER}+/ \mathrm{Her} 2+$} & 4 & 0 & 5 & 0 & \\
\hline & Totals & 20 & 121 & 17 & $P<0.001$ \\
\hline \multicolumn{6}{|c|}{ All samples (standardized TxP and RT-PCR) } \\
\hline ER-/Her2- & 26 & 31 & 52 & 60 & \\
\hline $\mathrm{ER}-/ \mathrm{Her} 2+$ & 10 & 0 & 20 & 0 & \\
\hline $\mathrm{ER}+/ \mathrm{Her} 2-$ & 57 & 2 & 116 & 2 & \\
\hline \multirow{2}{*}{$\mathrm{ER}+/ \mathrm{Her} 2+$} & 7 & 0 & 15 & 0 & \\
\hline & Totals & 33 & 203 & 16 & $P<0.001$ \\
\hline
\end{tabular}




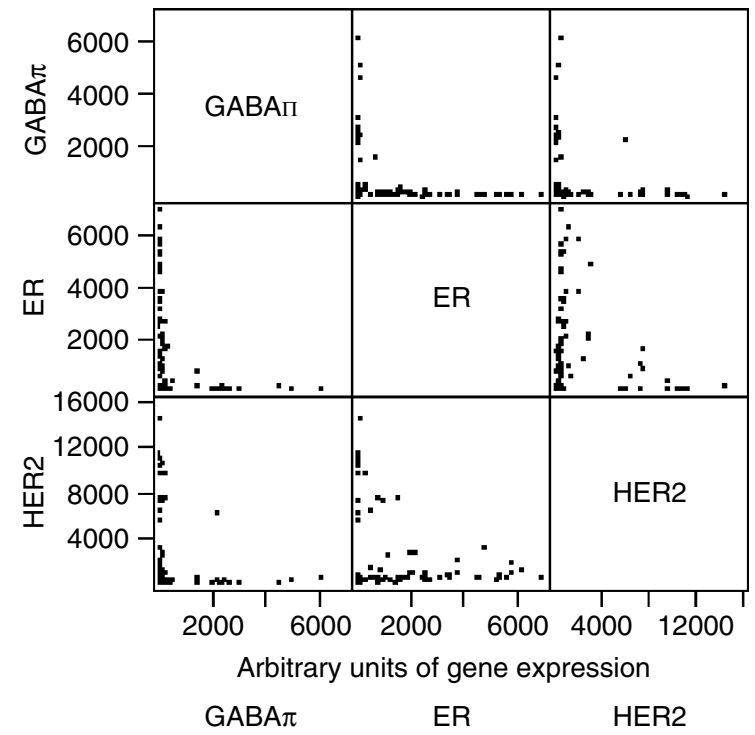

Figure 2 Scatterplot matrix demonstrating bivariate comparisons of gene-expression levels for ER, HER2 and GABA $\pi$ from the transcriptional profiles of 82 breast cancers. Expression values are arbitrary units.

luminal, HER2+, normal-like and basal-like subsets, using the intrinsic gene set described by Perou et al. (2000b) and Sorlie et al. (2001, 2003). All 13 tumors with high GABA $\pi$ gene expression had basal-like genomic profile, and those constituted $60 \%(13 / 22)$ of that genomic group. The majority of basal-like tumors $(18 / 22,82 \%)$ had ER-/HER2- phenotype, although three tumors had ER-/HER2+, and one tumor had ER+/HER2- phenotype. Conversely, the genomic classification of 22 ER-/HER2- breast cancers included 18 basal-like profiles $(82 \%)$, three normallike profiles and one HER2+ profile. Thirteen breast cancers had high GABA $\pi$ expression, and all of those tumors had ER-/HER2- phenotype and basal-like genomic profile. High GABA $\pi$ expression was identified in $72 \%(13 / 18)$ of basal-like tumors that were also ER-/HER2-. GABA $\pi$ gene expression alone accurately identified basal-like tumors with positive predictive value of 0.93 , specificity of 0.98 , negative predictive value of 0.87 and sensitivity of 0.59 . The 82 transcriptional profiles were also used to identify genes that were strongly coexpressed with GABA $\pi$. Fifteen genes had a Spearman rank correlation coefficient of $\geq 0.6$ (Table 2).

The distribution of clinical and pathologic characteristics that were evaluated in the 203 women was as follows: median age at diagnosis, race $(70 \%$ white, $11 \%$ black, $12 \%$ Hispanic and $7 \%$ other; $n=203$ ), family history of breast or ovarian cancer in a firstdegree relative $(83 \%$ none and $17 \%$ any; $n=202)$, reproductive history $(n=199$ : gravida $(11 \% \mathrm{G} 0,8 \%$ G1, 30\% G2, 25\% G3 and $28 \% \geq \mathrm{G} 4)$, parity $(15 \%$ $\mathrm{P} 0,10 \% \mathrm{P} 1,36 \% \mathrm{P} 2,23 \% \mathrm{P} 3$ and $17 \% \geq \mathrm{P} 4)$, abortion (68\% $\mathrm{AB} 0,20 \% \mathrm{AB} 1$ and $12 \% \geq \mathrm{AB} 2)$, age at first pregnancy $(12 \% \mathrm{G} 0,22 \%, \leq 19,31 \% 20-24$, $23 \% 25-29$ and $11 \% \geq 30 ; n=180$ ), lactation history as lifetime duration of breastfeeding ( $52 \%$ none, $18 \%$ $\leq 6$ months, $14 \% 6-12$ months and $15 \% \geq 12$ months;

Table 2 Genes with expression most strongly correlated with GABA $\pi$ expression (Spearman rank correlation coefficient of $\geq 0.6$ ) in the 82 TxPs are annotated by GenBank accession and gene symbol

\begin{tabular}{llll}
\hline $\begin{array}{l}\text { Correlation } \\
\text { coefficient }\end{array}$ & Accession no. & \multicolumn{1}{c}{ Gene name } & Gene symbol \\
\hline 0.771 & NM_003012.2 & Secreted frizzled-related protein 1 & SFRP1 \\
0.725 & NM_002423.2 & Matrix metalloproteinase 7 & MMP7 \\
0.698 & NM_002888.1 & Retinoic acid receptor responder 1 & RARRES1 \\
0.696 & NM_000424.1 & Keratin 5 & KRT5 \\
0.695 & AF016004.1 & Glycoprotein M6B & GPM6B \\
0.689 & BC003610.1 & Milk fat globule-EGF factor 8 protein & MFGE8 \\
0.684 & Al367319 & SRY (sex-determining region Y)-box 10 & SOX10 \\
0.659 & NM_006533.1 & Melanoma inhibitory activity & MIA \\
0.637 & NM_000222.1 & V-kit Hardy-Zuckerman 4 feline sarcoma viral oncogene homolog & KIT \\
0.628 & Al831452 & Keratin 6B & KRT6B \\
0.626 & NM_003986.1 & Butyrobetaine (gamma), 2-oxoglutarate dioxygenase & BBOX1 \\
0.625 & NM_000422 & Kamma-butyrobetaine hydroxylase)1 & KRT17 \\
0.62 & NM_002852.1 & Peratin 17 & PTX3 \\
0.616 & NM_017578 & Ropporin, rhophilin-associated protein 1 & ROPN1 \\
0.612 & NM_002639.1 & Serine proteinase inhibitor, clade B (ovalbumin), member 5 & SERPINB5 \\
0.609 & BC002690.1 & Keratin 14 & KRT14 \\
0.6 & NM_007231 & Solute carrier family 6 (neurotransmitter transporter), member 14 & SLC6A14 \\
\hline
\end{tabular}


$n=138$ ), grade (11\% low, $41 \%$ intermediate and $48 \%$ high; $n=203)$, tumor stage $(44 \% \mathrm{~T} 1,37 \% \mathrm{~T} 2,11 \% \mathrm{~T} 3$ and $8 \% \mathrm{~T} 4 ; n=203)$ and regional nodal stage $(54 \%$ $\mathrm{N} 0,32 \% \mathrm{~N} 1,6 \% \mathrm{~N} 2$ and $7 \% \mathrm{~N} 3 ; n=203$ ).

Linear regression analyses were used to compare the standardized GABA $\pi$ gene expression values with each of the clinical and pathologic characteristics in univariate ANOVA analyses. GABA $\pi$ gene expression level was positively associated with ER-/HER2phenotype $(P<0.0001)$, younger age at diagnosis $(P=0.0021)$, and lifetime duration of breastfeeding of $\leq 6$ months in all women $(P=0.036)$, and specifically in parous women $(P=0.012)$. The mean age of 33 patients whose breast cancer had high GABA $\pi$ expression was 52.8 years, compared with 55.7 years in the other 170 patients. Higher grade had borderline positive association with GABA $\pi$ gene expression level $(P=0.063)$. There was no association with tumor stage, nodal stage, race, number of pregnancies, births or abortions, age at first gestation, or family history of first-degree relative with breast or ovarian cancer.

Multivariate ANOVA analysis of the standardized GABA $\pi$ gene expression values included the following variables as main effects: phenotype (ER-/HER2-, all others), tumor stage, nodal stage, grade, age at diagnosis, race, number of pregnancies, births, abortions, age at first gestation, family history of firstdegree relative with breast or ovarian cancer, and duration of breast feeding. In this multivariate model $(\mathrm{R}$-square $=0.52$ ), positive association was observed between GABA $\pi$ expression level and ER-/HER2phenotype $(P<0.0001)$, younger age at diagnosis $(P=0.0003)$ and lifetime breastfeeding of $\leq 6$ months $(P=0.0173)$, including patients who were nulliparous, never breastfed, or reported a lifetime history of breastfeeding of $\leq 6$ months. Higher grade had a negative association with GABA $\pi$ expression $(P=0.0058)$, but there was a significant interaction with ER-/HER2- phenotype (described below). Considering only the subset of parous women $(P>0)$, we still found that GABA $\pi$ expression was associated with lifetime breastfeeding of $\leq 6$ months in this multivariate main effects model $(P=0.013)$. The other significant variables were unchanged when univariate and main effects multivariate analyses were repeated in this subset of parous women. A second multivariate analysis included all the variables in the first multivariate analysis as well as all the two-way interactions with ER-/HER2- phenotype, grade and age at diagnosis $(\mathrm{R}$-square $=0.67)$. The combination of ER-/HER2 - phenotype and high grade was positively associated with GABA $\pi$ expression
$(P=0.0018)$. Indeed, all tumors with high-grade and high GABA $\pi$ expression also had ER-/HER2phenotype (data not shown). Younger age at diagnosis continued to be significantly associated with GABA $\pi$ expression level when two-way interactions were included in the multivariate analysis $(P=0.0248)$. Although we did not observe any association between GABA $\pi$ gene expression and any one of the four ethnic groups in our univariate or main-effects multivariate analyses, there was a significant positive association between GABA $\pi$ gene expression level and an interaction term for the combination of Hispanic ethnicity and high-grade breast cancer $(P=0.036)$.

Despite the association of higher GABA $\pi$ gene expression with younger age at diagnosis and high grade, there was no observed association with $\mathrm{T}$-stage, $\mathrm{N}$-stage or any family history of first-degree relative with breast or ovarian cancer. It is therefore unlikely that GABA $\pi$ expression is directly related to tumor progression or to familial breast cancer. GABA $\pi$ expression was also not associated with reproductive history (gravida, parity or abortion) or age at first pregnancy. Follow-up has been short, and there have been too few recurrence events to date for us to evaluate survival or progression outcomes in this population.

\section{Discussion}

The finding of high GABA $\pi$ gene expression in approximately $60 \%$ of ER-/HER2- invasive breast cancers from 82 TxPs (Affymetrix U133A microarrays) was independently confirmed in an independent cohort of 121 samples by RT-PCR (Fig. 1 and Table 1). Expression of GABA $\pi$, ESR1 (ER) and ERBB2 (HER2) genes in the TxPs appears to be mutually exclusive (Fig. 2), suggesting that elevated GABA $\pi$ expression represents a divergent lineage of differentiation from ER and HER2, or that it represents a relatively undifferentiated cell type. There was an association between GABA $\pi$ gene expression and the least differentiated basal-like genomic profile (Perou et al. 2000a, Sorlie et al. 2001, 2003), and the genes that were coexpressed with GABA $\pi$ also indicate an immature cell type.

Five genes that were strongly coexpressed with GABA $\pi$ are known to distinguish the basal-like subset of breast cancers: KRT5, KRT6, KRT17, KIT and MFGE8 (Table 2). KRT5, KRT6 and KRT14 encode cytokeratins 5, 6 and 14, which are expressed in immature breast epithelial cells, although there is controversy as to whether expression of these cytokeratins is restricted to stem cells or includes other immature 
progenitor cells (Bocker et al. 2002, Abd El-Rehim et al. 2004, Clarke et al. 2004). KIT is a recognized stem cell factor receptor (Baghestanian et al. 2002). MFGE8 (milk fat globulin-EGF factor 8 protein) (lactadherin) is highly expressed during lactation and plays a role in the attachment of basal cells to the basement membrane through $\alpha v \beta 3$ integrins (Taylor et al. 1997). Other genes coexpressed with GABA $\pi$ (Table 2) are not included in the basal-like profile, but are expressed in immature epithelial and/or neuroepithelial cells. SFRP1 enhances cellular survival and is a secreted inhibitor of Wnt-induced signaling (Han \& Amar 2004). SFRP1 is expressed in specific epithelial cells during embryogenesis, including the lens and salivary gland (Leimeister et al. 1998, Chen et al. 2004). Although SFRP1 expression was lost in approximately $80 \%$ of breast cancers (described as ER-positive), expression was seen in a minority of breast cancers that were high-grade, ER-negative and described as having medullary histologic appearance (Ugolini et al. 2001). GPM6B (glycoprotein M6B) is expressed early in embryonic development of the central nervous system (Narayanan et al. 1998). SOX-10 is a transcription factor that is associated with neural precursor cells in the peripheral nervous system, including the enteric nervous system (Suarez-Rodriguez \& Belkind-Gerson 2004). MMP7 is a matrix metalloproteinase enzyme that contributes to embryogenesis and to tumor invasion by aiding in the degradation of the extracellular matrix (Hulboy et al. 2004, Kitoh et al. 2004). Coexpression of these genes with GABA $\pi$ illustrates the immature cell type of this subset of breast cancers.

There is a recognized overlap between inherited BRCA-1-associated breast cancer and tumors with the basal-like genomic profile. A recent study of Ashkenazi Jewish women from Montreal employed immunohistochemical (IHC) expression of CK 5/6 (KRT5 and KRT6) to define basal-like phenotype in $38 \%$ of 247 breast cancers (Foulkes et al. 2004). CK 5/6 expression was identified in $74 \%$ of their breast cancers in women who carried germ-line mutation of BRCA-1 gene ( $11 \%$ of the population studied), compared with $34 \%$ of breast cancers in women who did not carry BRCA-1 gene mutation (Foulkes et al. 2004). The same authors previously reported that $88 \%$ of ER-/HER 2 - breast cancers in BRCA-1 mutation carriers are CK 5/6positive (basal-like), compared with $45 \%$ of ER-/ HER2- breast cancers in noncarriers (Foulkes et al. 2003). Although higher GABA $\pi$ expression was associated with younger age at diagnosis in our linear regression analyses, we did not identify any association with family history of breast or ovarian cancer in a first-degree relative, and the mean age of 52.8 years in those with high GABA $\pi$ expression is older than might be expected for familial breast cancer. The BRCA-1 mutation carrier status of our patients is not known, but we observed no overlap between the genes that were coexpressed with GABA $\pi$ in our study (Table 2) and the genes that were reported to characterize BRCA-1 associated breast cancer (Hedenfalk et al. 2001). The undifferentiated tumors with GABA $\pi$ expression are diagnosed at a slightly younger age, but are probably not inherited.

Variable abrogation of cellular differentiation from oncogenesis produces breast cancers with different phenotypic and genomic characteristics. Furthermore, the molecular potency of a specific oncogenic insult, combined with the stage in cellular differentiation when breast epithelial cells are most susceptible to that specific oncogenic insult, has a profound effect on the level of differentiation of the breast cancer that ensues. That is why there is overlap among high-grade breast cancer, the ER-/HER2- phenotype, the basal-like genomic profile, breast cancer in BRCA-1 mutation carriers, and aberrations of important molecules such as p53, cyclin E, p27 and myc. These undifferentiated forms of breast cancer arise from early abrogation of cellular differentiation due to potent oncogenic insults. In this context, it is possible that elevated GABA $\pi$ gene expression is simply a biomarker for cellular immaturity, and not overexpression of a putative oncogene. However, the markedly elevated expression levels of GABA $\pi$ in undifferentiated breast cancers offers some hope that this molecule may have functional relevance that could one day be exploited for diagnostic, preventive and/or therapeutic uses. If GABA $\pi$ is a biomarker of progenitor breast cells and can be manipulated to induce differentiation, it could present a useful chemoprevention target for populations at risk of undifferentiated breast cancer.

Numerous studies have reported that breastfeeding decreases the risk of breast cancer, and that the lifetime duration of breastfeeding is inversely associated with risk (Yoo et al. 1992, Enger et al. 1997, Newcomb 1997, Lipworth et al. 2000, Purwanto et al. 2000, Collaborative Group 2002). A recent meta-analysis estimated a decrease in lifetime risk of breast cancer of $7 \%$ for every birth and $4 \%$ for every 12 months of breastfeeding (Collaborative Group 2002). However, there are only limited data linking lactation history with the phenotype of subsequent breast cancer. A history of previous breastfeeding was significantly associated with ER-positive breast cancer in one study of 148 patients, but was not associated with ER status in two other studies (Hildreth et al. 1983, Montgomery et al. 1985, McTiernan et al. 1986). Breastfeeding for 
$\geq 12$ months was associated with decreased risk of developing HER2-positive breast cancer (gene amplification), but not HER2-negative breast cancer, in one study of 577 women (Huang et al. 2000).

The biologic reasons for the protective effect of prolonged breastfeeding are unknown, but proposed mechanisms include decreased blood and/or breast fluid estrogen levels, delayed re-establishment of ovulation, excretion of carcinogens in milk, higher $\mathrm{pH}$ in milk and extended terminal differentiation of breast epithelium (Lipworth et al. 2000). During pregnancy, there is proliferative expansion of progenitor cells that express cytokeratins 5, 6 and 14 within breast lobules (Bocker et al. 2002). These genes (KRT5, KRT6 and KRT14) are coexpressed with GABA $\pi$ (Table 2). Breastfeeding leads to progressive loss of this expanded progenitor cell population through terminal differentiation of epithelial cells in the lobules (Smith et al. 1990, Russo \& Russo 1994, Bocker et al. 2002). Therefore, it follows that full-term pregnancy followed by a short duration of lactation may lead to retention of progenitor cells within the breast lobules in some women (Russo \& Russo 1994). Malignant transformation of retained progenitor cells would halt cellular differentiation at an early stage and lead to undifferentiated breast cancer. Our results tend to support this hypothesis, but larger and more detailed biologic and molecular epidemiologic studies are still required.

Hispanic ethnicity and the combined interaction of Hispanic ethnicity with high tumor grade were positively associated with GABA $\pi$ gene expression. The incidence of breast cancer has historically been lower in Hispanic women in the USA, but it has risen in recent years more quickly in this ethnic group than in others (Hunter 2000). Other studies have also shown that Hispanic women present with breast cancer of higher stage of disease (Daly et al. 1985, Natarajan et al. 1985, Mandelblatt et al. 1991, Bentley et al. 1998, Hedeen \& White 2001), and at a younger age than nonHispanic white women (Elledge et al. 1994, Zaloznik 1997). Access to health care and socioeconomic status probably do not explain these observed differences (Zaloznik 1997, Bentley et al. 1998). The survival of Hispanic women with breast cancer is worse than for non-Hispanic white women, but better than for black women, when controlled for age, stage, histology and treatment (Boyer-Chammard et al. 1999). It has also been reported that breastfeeding is relatively protective against subsequent breast cancer in African-American women more than in Caucasian women, and in Caucasian women more than in Hispanic women (Mayberry \& Stoddard-Wright 1992, Gilliland et al.
1998). However, prolonged breastfeeding was relatively protective against breast cancer in premenopausal Hispanic women (Gilliland et al. 1998). Undifferentiated breast cancer was independently associated with the combination of Hispanic ethnicity and high-grade invasive breast cancer in our multivariate analysis. This suggests that the lifetime duration of lactation, age at diagnosis or phenotype does not completely explain the association of GABA $\pi$ expression with Hispanic ethnicity in our study.

There is no significant difference in the frequency of ER-negative status in Hispanic women compared with other groups (Elledge et al. 1994, Hedeen \& White 2001). The frequency of HER2-positive and/or p53-positive invasive breast cancer is also similar in Hispanic and non-Hispanic white women (Hunter 2000). We note that Hispanic patients in our patient population include women who have always lived in Latin America, those who emigrated to the USA and those who were born in the USA. There may be differences in the epidemiology and pathology of breast cancers in these different groups of Hispanic patients (Hedeen \& White 2001). We believe the observed association between GABA $\pi$ gene expression and high-grade breast cancers in Hispanic women requires further study, but this does shed a different light on the molecular pathology of breast cancer in Hispanic women.

It is likely that elevated GABA $\pi$ gene expression represents a relatively undifferentiated subset of ER-/ HER2- breast cancers with high nuclear grade, presentation at a slightly younger age and association with shorter duration of lifetime breastfeeding. Shorter lifetime duration of breastfeeding may predispose to future development of undifferentiated and estrogenindependent breast cancer, possibly due to retention of progenitor cells and their failure to undergo terminal differentiation. Further study is needed to ascertain the biologic role of GABA $\pi$ in the breast and to explore the potential therapeutic or preventive strategies for breast cancer.

\section{Funding}

This work was supported by institutional research funds (W F S), a research grant from Millennium Pharmaceuticals, Inc., Cambridge, MA (L P), and the Tobacco Settlement Fund as appropriated to the University of Texas M D Anderson Cancer Center by the Texas Legislature and by generous donations from the Kadoorie Foundation (Core Genomics Facility). The authors declare that there is no conflict of interest that would prejudice the impartiality of this scientific work. 


\section{References}

Abd El-Rehim DM, Pinder SE, Paish CE, Bell J, Blamey RW, Robertson JF, Nicholson RI \& Ellis IO 2004 Expression of luminal and basal cytokeratins in human breast carcinoma. Journal of Pathology 203 661-671.

Baghestanian M, Jordan JH, Kiener HP, Bevec D, Agis H, Fritsch G, Muller MR, Bankl HC, Schernthaner GH, Lechner K et al. 2002 Activation of human mast cells through stem cell factor receptor (KIT) is associated with expression of bcl-2. International Archives in Allergy and Immunology 129 228-236.

Bentley JR, Delfino RJ, Taylor TH, Howe S \& Anton-Culver H 1998 Differences in breast cancer stage at diagnosis between non-Hispanic white and Hispanic populations, San Diego County 1988-1993. Breast Cancer Research and Treatment 50 1-9.

Bocker W, Moll R, Poremba C, Holland R, Van Diest PJ, Dervan P, Burger H, Wai D, Ina Diallo R, Brandt B et al. 2002 Common adult stem cells in the human breast give rise to glandular and myoepithelial cell lineages: a new cell biological concept. Laboratory Investigations $\mathbf{8 2}$ 737-746.

Boyer-Chammard A, Taylor TH \& Anton-Culver H 1999 Survival differences in breast cancer among racial/ethnic groups: a population-based study. Cancer Detection and Prevention 23 463-473.

Chen Y, Stump RJ, Lovicu FJ \& McAvoy JW 2004 Expression of frizzleds and secreted frizzled-related proteins (Sfrps) during mammalian lens development. International Journal of Developmental Biology 48 867-877.

Clarke CL, Sandle J, Parry SC, Reis-Filho JS, O'Hare MJ \& Lakhani SR 2004 Cytokeratin 5/6 in normal human breast: lack of evidence for a stem cell phenotype. Journal of Pathology 204 147-152.

Collaborative Group 2002 Breast cancer and breastfeeding: collaborative reanalysis of individual data from 47 epidemiological studies in 30 countries, including 50302 women with breast cancer and 96973 women without the disease. Lancet 360 187-195.

Daly MB, Clark GM \& McGuire WL 1985 Breast cancer prognosis in a mixed Caucasian-Hispanic population. Journal of the National Cancer Institute 74 753-757.

Elledge RM, Clark GM, Chamness GC \& Osborne CK 1994 Tumor biologic factors and breast cancer prognosis among white, Hispanic, and black women in the United States. Journal of the National Cancer Institute $\mathbf{8 6}$ 705-712.

Elledge RM, Green S, Pugh R, Allred DC, Clark GM, Hill J, Ravdin P, Martino S \& Osborne CK 2000 Estrogen receptor $(\mathrm{ER})$ and progesterone receptor $(\mathrm{PgR})$, by ligand-binding assay compared with ER, $\mathrm{PgR}$ and $\mathrm{pS} 2$, by immuno-histochemistry in predicting response to tamoxifen in metastatic breast cancer: a Southwest Oncology Group Study. International Journal of Cancer 89 111-117.
Enger SM, Ross RK, Henderson B \& Bernstein L 1997 Breastfeeding history, pregnancy experience and risk of breast cancer. British Journal of Cancer $\mathbf{7 6}$ 118-123.

Foulkes WD, Stefansson IM, Chappuis PO, Begin LR, Goffin JR, Wong N, Trudel M \& Akslen LA 2003 Germline BRCA1 mutations and a basal epithelial phenotype in breast cancer. Journal of the National Cancer Institute 95 1482-1485.

Foulkes WD, Brunet JS, Stefansson IM, Straume O, Chappuis PO, Begin LR, Hamel N, Goffin JR, Wong N, Trudel M et al. 2004 The prognostic implication of the basal-like (cyclin E high/p27 low/p53 + /glomeruloidmicrovascular-proliferation + ) phenotype of BRCA1related breast cancer. Cancer Research 64 830-835.

Fujii E \& Mellon SH 2001 Regulation of uterine gammaaminobutyric acid A receptor subunit expression throughout pregnancy. Endocrinology 142 1770-1777.

Gilliland FD, Hunt WC, Baumgartner KB, Crumley D, Nicholson CS, Fetherolf J \& Samet JM 1998 Reproductive risk factors for breast cancer in Hispanic and non-Hispanic white women: the New Mexico Women's Health Study. American Journal of Epidemiology 148 683-692.

Han X \& Amar S 2004 Secreted frizzled-related protein 1 (SFRP1) protects fibroblasts from ceramide-induced apoptosis. Journal of Biological Chemistry 279 2832-2840.

Harvey JM, Clark GM, Osborne CK \& Allred DC 1999 Estrogen receptor status by immunohistochemistry is superior to the ligand-binding assay for predicting response to adjuvant endocrine therapy in breast cancer. Journal of Clinical Oncology 17 1474-1481.

Hedblom E \& Kirkness EF 1997 A novel class of GABAA receptor subunit in tissues of the reproductive system. Journal of Biological Chemistry 272 15346-15350.

Hedeen AN \& White E 2001 Breast cancer size and stage in Hispanic American women, by birthplace: 1992-1995. American Journal of Public Health 91 122-125.

Hedenfalk I, Duggan D, Chen Y, Radmacher M, Bittner M, Simon R, Meltzer P, Gusterson B, Esteller M, Kallioniemi OP et al. 2001 Gene-expression profiles in hereditary breast cancer. New England Journal of Medicine 344 539-548.

Hildreth NG, Kelsey JL, Eisenfeld AJ, LiVolsi VA, Holford TR \& Fischer DB 1983 Differences in breast cancer risk factors according to the estrogen receptor level of the tumor. Journal of the National Cancer Institute $\mathbf{7 0}$ 1027-1031.

Huang WY, Newman B, Millikan RC, Conway K, Hulka BS, Schell MJ \& Liu ET 2000 Risk of breast cancer according to the status of HER-2/neu oncogene amplification. Cancer Epidemiology, Biomarkers and Prevention 9 65-71.

Hulboy DL, Gautam S, Fingleton B \& Matrisian LM 2004 The influence of matrix metalloproteinase-7 on early mammary tumorigenesis in the multiple intestinal neoplasia mouse. Oncology Reports 12 13-17. 
Hunter CP 2000 Epidemiology, stage at diagnosis, and tumor biology of breast carcinoma in multiracial and multiethnic populations. Cancer 88, 1193-1202.

Jernstrom H, Lubinski J, Lynch HT, Ghadirian P, Neuhausen S, Isaacs C, Weber BL, Horsman D, Rosen B, Foulkes WD et al. 2004 Breast-feeding and the risk of breast cancer in BRCA1 and BRCA2 mutation carriers. Journal of the National Cancer Institute $\mathbf{9 6}$ 1094-1098.

Jiang Y, Harlocker SL, Molesh DA, Dillon DC, Stolk JA, Houghton RL, Repasky EA, Badaro R, Reed SG \& Xu J 2002 Discovery of differentially expressed genes in human breast cancer using subtracted cDNA libraries and cDNA microarrays. Oncogene 21 2270-2282.

Kitoh T, Yanai H, Saitoh Y, Nakamura Y, Matsubara Y, Kitoh H, Yoshida T \& Okita K 2004 Increased expression of matrix metalloproteinase-7 in invasive early gastric cancer. Journal of Gastroenterology 39 434-440.

Laurie DJ, Wisden W \& Seeburg PH 1992 The distribution of thirteen GABAA receptor subunit mRNAs in the rat brain. III. Embryonic and postnatal development. Journal of Neuroscience 12 4151-4172.

Leimeister C, Bach A \& Gessler M 1998 Developmental expression patterns of mouse sFRP genes encoding members of the secreted frizzled related protein family. Mechanisms of Development 75 29-42.

Li C \& Hung Wong W 2001 Model-based analysis of oligonucleotide arrays: model validation, design issues and standard error application. Genome Biology $\mathbf{2}$ RESEARCH0032.

Lipworth L, Bailey LR \& Trichopoulos D 2000 History of breast-feeding in relation to breast cancer risk: a review of the epidemiologic literature. Journal of the National Cancer Institute 92 302-312.

Majewska MD, Falkay G \& Baulieu EE 1989 Modulation of uterine GABAA receptors during gestation and by tetrahydroprogesterone. European Journal of Pharmacology 174 43-47.

Mandelblatt J, Andrews H, Kerner J, Zauber A \& Burnett W 1991 Determinants of late stage diagnosis of breast and cervical cancer: the impact of age, race, social class, and hospital type. American Journal of Public Health 81, 646-649.

Mayberry RM \& Stoddard-Wright C 1992 Breast cancer risk factors among black women and white women: similarities and differences. American Journal of Epidemiology 136 1445-1456.

McTiernan A, Thomas DB, Johnson LK \& Roseman D 1986 Risk factors for estrogen receptor-rich and estrogen receptor-poor breast cancers. Journal of the National Cancer Institute 77 849-854.

Montgomery AC, McClelland RA, Skilton RA \& Easton D 1985 Risk factors and clinical data related to oestrogen receptor status in women presenting with breast cancer. British Journal of Surgery 72 629-633.

Narayanan V, Olinsky S, Dahle E, Naidu S \& Zoghbi HY 1998 Mutation analysis of the M6b gene in patients with
Rett syndrome. American Journal of Medical Genetics $\mathbf{7 8}$ 165-168.

Natarajan N, Nemoto T, Mettlin C \& Murphy GP 1985 Race-related differences in breast cancer patients. Results of the 1982 national survey of breast cancer by the American College of Surgeons. Cancer 56 1704-1709.

Neelands TR \& Macdonald RL 1999 Incorporation of the pi subunit into functional gamma-aminobutyric acid(A) receptors. Molecular Pharmacology 56 598-610.

Newcomb PA 1997 Lactation and breast cancer risk. Journal of Mammary Gland Biology and Neoplasia 2 311-318.

Nielsen TO, Hsu FD, Jensen K, Cheang M, Karaca G, Hu Z, Hernandez-Boussard T, Livasy C, Cowan D, Dressler L et al. 2004 Immunohistochemical and clinical characterization of the basal-like subtype of invasive breast carcinoma. Clinical Cancer Research 10 5367-5374.

Ogura H, Akiyama F, Kasumi F, Kazui T \& Sakamoto G 2003 Evaluation of HER-2 status in breast carcinoma by fluorescence in situ hybridization and immunohistochemistry. Breast Cancer 10 234-240.

Perou CM, Sorlie T, Eisen MB, van de Rijn M, Jeffrey SS, Rees CA, Pollack JR, Ross DT, Johnsen H, Akslen LA et al. 2000 a Molecular portraits of human breast tumours. Nature 406 747-752.

Perou CM, Sùrlie T, Eisen MB, van de Rijn M, Jeffrey SS, Rees CA, Pollack JR, Ross DT, Johnsen H, Akslen LA et al. $2000 \mathrm{~b}$ Molecular portraits of human breast tumours. Nature 406 747-752.

Purwanto H, Sadjimin T \& Dwiprahasto I 2000 Lactation and the risk of breast cancer. Gan To Kagaku Ryoho 27 (Suppl 2) 474-481.

Pusztai L, Ayers M, Stec J, Clark E, Hess K, Stivers D, Damokosh A, Sneige N, Buchholz TA, Esteva FJ et al. 2003 Gene expression profiles obtained from single passage fine needle aspirations (FNA) of breast cancer reliably identify prognostic/predictive markers such as estrogen (ER) and HER-2 receptor status and reveal large scale molecular differences between ER-negative and ER-positive tumors. Clinical Cancer Research 9 2406-2415.

Russo J \& Russo IH 1994 Toward a physiological approach to breast cancer prevention. Cancer Epidemiology, Biomarkers and Prevention 3 353-364.

Sapino A, Coccorullo Z, Cassoni P, Ghisolfi G, Gugliotta P, Bongiovanni M, Arisio R, Crafa P \& Bussolati G 2003 Which breast carcinomas need HER-2/neu gene study after immunohistochemical analysis? Results of combined use of antibodies against different c-erbB2 protein domains. Histopathology 43 354-362.

Smith GH, Mehrel T \& Roop DR 1990 Differential keratin gene expression in developing, differentiating, preneoplastic, and neoplastic mouse mammary epithelium. Cell Growth Differentiation 1 161-170.

Sorlie T, Perou CM, Tibshirani R, Aas T, Geisler S, Johnsen H, Hastie T, Eisen MB, van de Rijn M, Jeffrey SS et al. 
2001 Gene expression patterns of breast carcinomas distinguish tumor subclasses with clinical implications. PNAS 98 10869-10874.

Sorlie T, Tibshirani R, Parker J, Hastie T, Marron JS, Nobel A, Deng S, Johnsen H, Pesich R, Geisler S et al. 2003 Repeated observation of breast tumor subtypes in independent gene expression data sets. PNAS 100 8418-8423.

Suarez-Rodriguez R \& Belkind-Gerson J 2004 Cultured nestin-positive cells from postnatal mouse small bowel differentiate ex vivo into neurons, glia, and smooth muscle. Stem Cells 22 1373-1385.

Symmans WF, Ayers M, Clark EA, Stec J, Hess KR, Sneige N, Buchholz TA, Krishnamurthy S, Ibrahim NK, Buzdar AU et al. 2003 Total RNA yield and microarray gene expression profiles from fine needle aspiration and core needle biopsy samples of breast cancer. Cancer 97 2960-2971.

Taylor MR, Couto JR, Scallan CD, Ceriani RL \& Peterson JA 1997 Lactadherin (formerly BA46), a membrane-associated glycoprotein expressed in human milk and breast carcinomas, promotes Arg-Gly-Asp
(RGD)-dependent cell adhesion. DNA Cell Biology 16 861-869.

Ugolini F, Charafe-Jauffret E, Bardou VJ, Geneix J, Adelaide J, Labat-Moleur F, Penault-Llorca F, Longy M, Jacquemier J, Birnbaum D et al. 2001 WNT pathway and mammary carcinogenesis: loss of expression of candidate tumor suppressor gene SFRP1 in most invasive carcinomas except of the medullary type. Oncogene $\mathbf{2 0}$ 5810-5817.

Yoo KY, Tajima K, Kuroishi T, Hirose K, Yoshida M, Miura S \& Murai H 1992 Independent protective effect of lactation against breast cancer: a case-control study in Japan. American Journal of Epidemiology 135 726-733.

Zaloznik AJ 1997 Breast cancer stage at diagnosis: Caucasians versus Hispanics. Breast Cancer Research and Treatment 42 121-124.

Zehentner BK, Dillon DC, Jiang Y, Xu J, Bennington A, Molesh DA, Zhang X, Reed SG, Persing D \& Houghton RL 2002 Application of a multigene reverse transcriptionPCR assay for detection of mammaglobin and complementary transcribed genes in breast cancer lymph nodes. Clinical Chemistry 48 1225-1231. 
